\title{
Stimulus control of schedule-induced aggression in the pigeon
}

\author{
JOHN M. COLE and PETER $M$. \\ LITCHFIELD, University of Portland, \\ Portland, Oreg. 97203
}

Two male homing pigeons were food deprived and placed on a multiple FR2-FR66 schedule with target birds present in the chamber. For both birds, a red and a green houselight signaled FR66 and FR2 components, respectively. As the birds learned the discrimination, as indicated by longer postreinforcement pauses in the red relative to the green light, aggressive behavior toward the target bird came under the control of the discriminative stimuli, i.e., occurred only in the postreinforcement interval of the red light. When the multiple schedule was reversed $\quad(F R 66=$ green,$\quad F R 2=$ red $)$ postreinforcement pausing and aggressive attack also reversed.

Aggressive behavior in animals is known to be caused by a variety of factors. In a natural environment, animals attack members of the same species for reasons of territoriality and competition for food or a mate. In the laboratory, recent investigations indicate that many species of animals will attack members of the same species, of different species, or even inanimate objects when exposed to such physically painful aversive stimulation as electric foot-shock (Ulrich, Hutchinson, \& Azrin, 1965), tail-shock (Azrin, Hutchinson, \& McLaughlin, 1965), or physical blows (Azrin, Hake, \& Hutchinson, 1965). In addition, it has been revealed that certain schedules of positive reinforcement are also aversive. This is demonstrated by the fact that organisms confronted with intermittent extinction or high fixed-ratio schedules avoid (Azrin, 1961) or escape (Thompson, 1964) from the schedule or are effectively punished by the presentation of such a schedule (Holz, Azrin \& Ayllon, 1963). As with physically painful aversive stimulation, it has been demonstrated that aversive schedules of positive reinforcement can also induce aggressive responses toward a target object. Azrin, Hutchinson, \& Hake (1966) found that when 5-min periods of extinction were intermittently given in a CRF schedule, pigeons attacked a target bird during the extinction periods. Similarly, Gentry (1968) found that when periods of extinction and FR50 were alternated in blocks of five 45 -min sessions, aggression occurred in the FR50 component but not in extinction.
The present experiment attempted to bring schedule-induced aggression under stimulus control, i.e., under the control of an originally neutral discriminative stimulus (SD). This was accomplished by using a two-component multiple schedule of positive reinforcement with each of the schedules being signaled by colored houselights. Thus, as the originally neutral $\mathrm{SD}_{\mathrm{S}}$ (red and green lights) came to signal whether an easy (FR2) or a difficult (FR66) schedule was in effect, the degree of stimulus control could be measured by the extent to which aggression occurred during the postreinforcement pause of the signaled FR66 relative to the signaled FR2 schedule of reinforcement.

SUBJECTS

Four male homing pigeons were used, two serving as experimental Ss and two as targets.

\section{APPARATUS}

A standard pigeon chamber, $14 \times 11 \times 11$ in., with only the left key operative, was used. Inserted into the right side of the chamber was a wooden restraint apparatus, $5 \frac{1}{2} \times 11 \times 11$ in., containing a $5 \times 5$ in. window opening into the upper-right-rear corner of the pigeon chamber. This opening made visual and/or physical contact between the experimental and restrained target birds possible. In addition to the standard white houselight, red and green 125-W floodlamps were placed approximately 18 in. above the houselight aperture, thus making any of the three colors of houselights available. Standard electromechanical programming equipment was used to control houselights, reinforcements, etc. A $2 \frac{1}{2} \times 4$ in. one-way mirror, located in the upper-left-rear corner of the pigeon chamber, allowed $\mathrm{E}$ a clear view of the experimental birds in all portions of the chamber. A two-channel event recorder with two hand-switches allowed $\mathrm{E}$ to record postreinforcement pauses and aggressive responses while observing.

\section{PROCEDURE}

All Ss were housed individually with ad lib access to grit and water. After being food deprived to $80 \%$ of their normal body weights, experimental Ss were (a) magazine trained, (b) shaped to peck the lighted left key, and (c) gradually taken to an FR66 schedule of reinforcement. During this initial phase, the white houselight was on, no target bird or restraint apparatus was present, and the left key was illuminated white. When both Ss were pecking rapidly on the FR66 schedule, the restraint apparatus containing a target bird was placed in the chamber. Upon habituation to the new environmental cues and a resumption of rapid FR66 responding, discrimination training was introduced.

Throughout each 48-trial daily block of discrimination training, a random order of FR2 and FR66 schedules was in effect, FR2 signaled by the green and FR66 by the red houselight. Since each FR schedule was signaled throughout a given trial, it was possible for Ss to learn which schedule was in effect before ever making a key-peck response. A discrete-trials procedure was used, with 15-sec blackouts immediately following each reinforcement.

During each daily trial sequence, $E$ observed the experimental $S$ through the one-way mirror and recorded (a) postreinforcment pause, defined as the time between trial onset and the first key-peck response made on that trial, and (b) aggressive behavior. By recording these two measures simultaneously, a record was made indicating when aggression occurred as well as how much aggression occurred.

In attempting to define an aggressive response adequately, the following criteria were used: (a) striking at the target bird with the head and beak, with or without actually striking the target bird (b) grasping with the beak any part of the target bird (primarily the head and beak) and violently shaking the target bird; (c) going through an apparently innate, ritualized response pattern consisting of repeatedly facing the target bird and turning back and forth in a 180-deg arc while bobbing the head up and down and cooing loudly. This latter response nearly always preceded and/or followed physical attack of the target bird. The use of this particular criterion of an aggressive response proved particularly effective and resulted in very little subjective decision-making as to whether a response was or was not "aggressive."

After approximately 300 trials on the initial discrimination, the contingencies were reversed so that the green houselight signaled FR66 and the red one, FR2. The reversed discrimination was continued for 168 trials. During this reversal, all procedures were exactly the same as those used in initial discrimination training. RESULTS AND DISCUSSION

The mean latency of aggression occurring during the postreinforcement interval of initial and reversed discrimination trials is shown in Fig. 1. Results clearly indicate that during the final seven blocks of the initial discrimination, both birds were aggressing only during the interval of the red light that signaled FR66. When the reinforcement contingencies were reversed so that the green light signaled FR66, 


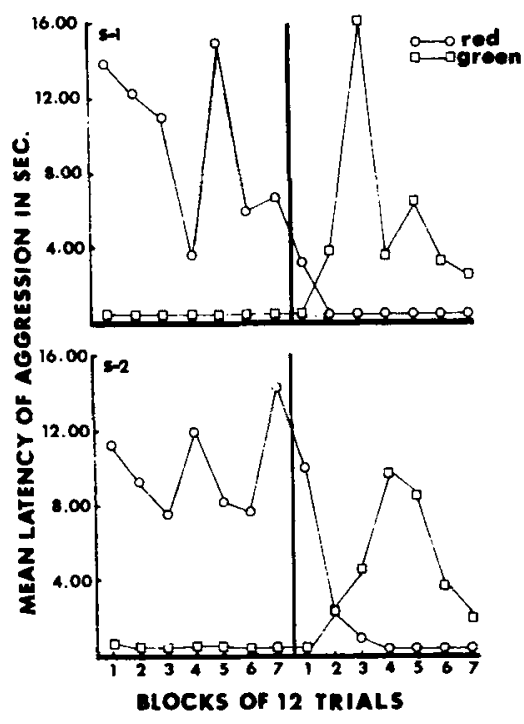

Fig. 1. Mean duration of aggressive responding during postreinforcement interval of the last seven blocks of discrimination (FR66 $=$ red, FR2 = green) and the first seven blocks of reversed discrimination (FR66 = green, FR2 = red).

aggression in both birds came under the control of the green light.

Total durations of aggression in the reversed phase seemed to be somewhat smaller than total durations in the initial phase; also, there was a trend toward less aggression in the latter blocks of the reversed phase for S-2. Phasing out of aggression in the present study would not be unpredicted, since studies of the innate fighting response in Betta splendens (Baenninger, 1966) have shown that aggressive responses do wane with repeated trials.

The present findings suggest that $S s$ do respond much differently in a "frustrating" situation, depending on whether or not an attackable target bird is present. More precisely, birds seem to have a natural tendency to aggress target objects when a relatively difficult response requirement is in effect, or when an $S^{D}$ signals that such a schedule is in effect. Although making the aggressive response has no effect on the food-reinforcement contingency and serves only to delay food reinforcement, the aggressive act would seem to have certain reinforcing properties of its own. Investigations are presently being conducted in the Es' laboratory to determine more precisely the nature of these reinforcing properties.

\section{REFERENCES}

AZRIN, N. H. Time-out from positive reinforcement. Science, 1961, 133, 382-383.
AZRIN, N. H., HAKE, D. F., \& HUTCHINSON, R. R. Elicitation of aggression by a physical blow. Journal of the Experimental Analysis of Behavior, 1965, 8, 55-57.

AZRIN, N. H., HUTCHINSON, R. R., \& HAKE, D. F. Extinction-induced aggression. Journal of the Experimental Analysis of Behavior, 1966, 9, 191-204.

AZRIN, N. H., HUTCHINSON, R. R., \& McLAUGHLIN, $R$. The opportunity for aggression as an operant reinforcer during aversive stimulation. Joumal of the Experimental Analysis of Behavior, 1965, 8, $171-180$.

BAENNINGER, R. Waning of aggressive motivation in Betta splendens. Psychonomic
Science, 1966, 4, 241-242.

GENTRY, W. D. Fixed-ratio schedule-induced aggression. Journal of the Experimental Analysis of Behavior, 1968, 11, 813-817.

HOLZ, W. C., AZRIN, N. H., \& AYLLON, T. Elimination of behavior of mental patients by response-produced extinction. Journal of the Experimental Analysis of Behavior, 1963, 6, 407-412.

THOMPSON, D. M. Punishment by $\mathrm{SD}^{\mathrm{D}}$ associated with fixed ratio reinforcement. Journal of the Experimental Analysis of Behavior, 1964, 7, $1-8$.

ULRICH, R. E., HUTCHINSON, R. R., \& AZRIN, N. H. Pain-licited aggression. Psychological Record, 1965, 15, 111-126.

\section{A quantitative genetic analysis of change in open- field behavior of mice ${ }^{1}$}

J. C. DeFRIES, University of Colorado, Boulder, Colo. 80302, J. P. HEGMANN, University of Iowa, lowa City, Iowa 52240, and DIANNE B. ROSS and $M$. KATHERINE HOWARD, University of Colorado, Boulder, Colo. 80302

Daily open-field activity and defecation scores were obtained on each of 2,641 mice, including members of two inbred parental strains (BALB/cJ and C57BL/6J) and their derived $F 1$, backcross, $F 2$, and F3 generations. Change in activity and change in defecation from Day 1 to Day 2 were calculated for each individual, and resulting scores were subjected to genetic analysis. Strain comparisons and estimates of heritability revealed proportionately less genetic variance for change in activity than for either daily or total activity. In contrast, change in defecation was found to be as heritable as the other defecation measures. These results suggest that change in activity in novel situations may be of evolutionary significance.

Although change in behavior as a function of experience is of considerable importance to the fields of psychology and evolution, little information is currently available regarding the inheritance of behavioral change (Broadhurst \& Jinks, 1966). Evidence for the presence of genetic variance among strains of mice in pattern of exploration in a $Y$ maze across successive test days has been provided by Brookshire \& Rieser (1967): In addition, some evidence for heritable differences in change in open-field defecation of rats across successive trials has been reported by Broadhurst \& Jinks (1966).

Open-field behavior is a widely employed index of emotionality; thus, change in this behavior may indicate change in motivational state. The primary objective of the present study was to conduct a quantitative genetic analysis of change in open-field behavior in mice. Such an analysis may provide information not only about the genetic architecture of behavioral change, but also about its evolutionary significance (Roberts, 1967).

\section{METHOD}

Daily open-field behavioral scores were obtained from 2,641 Ss, including members of two inbred parental strains of mice (BALB/cJ and C57BL/6J) and their derived $F 1$, backcross, F2, and F3 generations. Each $S$ was tested for $3 \mathrm{~min}$ on 2 consecutive days at $40 \pm 5$ days of age in a brightly lighted open field $(36 \times 36$ in.) constructed of white, painted Plexiglas. Two sets of five light sources on adjacent sides of the field were beamed through red filters and holes to photoconductive cells on the opposite sides. This divided the floor of the field in to 36 squares ( $6 \times 6$ in. each) and activity was automatically recorded as individuals interrupted the beams. The number of fecal 